\title{
Article \\ Impact Properties of Novel Natural Fibre Metal Laminated Composite Materials
}

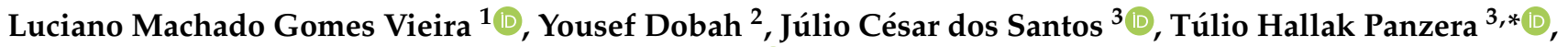 \\ Juan Carlos Campos Rubio ${ }^{1}$ and Fabrizio Scarpa ${ }^{4, *(1)}$
}

1 School of Engineering, Federal University of Minas Gerais, Belo Horizonte 31270-901, Brazil; lucianomgv@yahoo.com.br (L.M.G.V.); juancarlos681@gmail.com (J.C.C.R.)

2 Department of Mechanical Engineering, University of Jeddah, Jeddah 21589, Saudi Arabia; ydobah@uj.edu.sa

3 Centre for Innovation and Technology in Composite Materials, Department of Mechanical and Production Engineering, Federal University of São João del Rei, São João del Rei 36301-158, Brazil; dsantosjcs@gmail.com

4 Bristol Composites Institute (ACCIS), University of Bristol, Bristol BS8 1TR, UK

* Correspondence: panzera@ufsj.edu.br (T.H.P.); f.scarpa@bristol.ac.uk (F.S.)

check for

updates

Citation: Vieira, L.M.G.; Dobah, Y.; dos Santos, J.C.; Panzera, T.H.; Campos Rubio, J.C.; Scarpa, F. Impact Properties of Novel Natural Fibre Metal Laminated Composite

Materials. Appl. Sci. 2022, 12, 1869.

https://doi.org/10.3390/

app12041869

Academic Editor: Georgios

I. Giannopoulos

Received: 7 August 2021

Accepted: 7 February 2022

Published: 11 February 2022

Publisher's Note: MDPI stays neutral with regard to jurisdictional claims in published maps and institutional affiliations.

Copyright: (c) 2022 by the authors. Licensee MDPI, Basel, Switzerland. This article is an open access article distributed under the terms and conditions of the Creative Commons Attribution (CC BY) license (https:// creativecommons.org/licenses/by/ $4.0 /)$.

\begin{abstract}
Fibre metal laminates (FMLs) are lightweight structures with high structural performance and are suitable for many industrial applications. This work describes the impact behaviour of novel sisal fibre-reinforced aluminium laminates (SiRAL) and their dependence upon the orientations of the fibres, the composite core used and the surface treatment of the metal skins. A cold-pressing technique is used to produce SiRALs in six configurations. The FMLs here also have treated or untreated aluminium skins (2024 T3) and three different types of core materials $\left(0^{\circ} / 90^{\circ}\right.$ fabric, $\pm 45^{\circ}$ fabric and random matt). The $\pm 45^{\circ}$ core treated SiRAL provides the highest energy absorption and deflection properties. The pre-treatment of aluminium skins using sandpaper, deep cleaning and primer significantly affects the delamination of the panels under bending impact. The findings reveal that the SiRAL concept is a promising multifunctional FML suitable for different applications that require lightweight, bending and impact performance, together with sustainability characteristics.
\end{abstract}

Keywords: fibre metal laminate; sisal fibres; impact; drop tower; fracture; composite

\section{Introduction}

Fibre metal laminate (FML) is a hybrid composite used in various applications, ranging from aerospace to construction fields. FMLs are based on the combination of polymeric layers from different fibre-reinforced laminates and thin metal sheets [1]. Classical aluminium alloys possess low damage tolerance and fatigue properties, but those can be enhanced by designing hybrid structures consisting of fibre-reinforced composites and metal layers [2].

During the last two decades, many FML concepts have been developed based on different polymeric reinforcements. Amongst them, it is worth mentioning commercial FMLs, such as ARALL (aramid), GLARE (glass) and CARALL (carbon) [3]. Several research groups have also expanded the FML baseline design in recent years. The authors of [4] introduced the use of $\mathrm{Co}-\mathrm{Fe}$ electric steel skins with magnetically susceptible properties for electrical machine applications. Carrillo and Cantwell [5] have developed a new thermoplastic matrix FML based on a self-reinforced polypropylene manufactured in a simple compression moulding process. This particular type of FML has been investigated to assess its impact behaviour and general mechanical properties. The demand for sustainable and eco-friendly materials has driven the development of FMLs based on natural fibres [6-8]. The use of natural fibres in FMLs, such as mixed jute/carbon [9] and bamboo [10], has shown promising behaviour for different structural applications [3]. In a previous work [11], the authors evaluated the mechanical properties of bidirectional SiRAL (0/90) for potential applications in the transport industry. Recently, two FMLs made from natural fibre composites were investigated under tensile and bending loading [12,13]. A kenaf bast 
fibre-reinforced polypropylene composite bonded to aluminium skins was developed by Malingam et al. [12], and 3D jute fibre composites with aluminium skins were evaluated by Hussain et al. [13]. The chemically treated kenaf/PP FMLs showed a significant increase in terms of tensile modulus and flexural strength $(\sim 74 \%)$ compared to the laminate composites with the chemically untreated kenaf fibres [12]. Jute-based FMLs with an interlocked 3D woven fabric architecture showed consistent larger mechanical properties than analogous jute fibre-reinforced composites [13].

Low-kinetic energy impacts are a likely occurrence during the service life of a structural composite. The resulting damage generated by these impacts is generally in the form of delamination. If the impact energy is large enough, fibre breakage and matrix failure can also be observed. Most low-velocity impact studies have been performed using hemispherical impactors $[14,15]$. Impact resistance is one of the most critical issues related to composite structures [2]. The resistance to impact perforation of a thermoplastic (polypropylene)-based fibre metal laminate was investigated, showing superiority to its monolithic aluminium and thermoset-based counterparts [5]. Laliberte et al. [16] analysed the impact response and post-impact fatigue behaviour of GLARE compared to 2024-T3 monolithic aluminium. The dynamic failure of fibre metal laminates was also investigated by [17]. Three types of woven fibre fabrics (basalt, S2-glass and Kevlar-29) were used to reinforce the aluminium sheets. Different deformation/failure modes of the FMLs were obtained by varying the impact energy. The results showed that the total deformation increased with the impact velocity. An evident reduction in total deformation could be observed after penetration. Damages to the FML panels, such as tearing of the aluminium ply, fibre fracture, matrix cracks and debonding/delamination, were also detected around the impact region. The results indicated that basalt-reinforced aluminium laminates perform very well in terms of impact resistance. Autoclaved carbon and glass FMLs (steel skins) have been tested under low-velocity impact [18]. These FMLs have been evaluated by considering the influence of different fibre stacking sequences. The crack propagation direction and the energy absorption rate of those FMLs were governed by fibre orientation [18]. Dhaliwal and Newaz [19] studied the dynamic response of CARALL (carbon fibre-reinforced aluminium laminates). In those FMLs, the amount of polymer was one of the main mechanisms leading to the increase in the impact peak force, as well as providing lower deflection and delamination areas. Jakubczak et al. [20] compared the low-velocity impact behaviour of conventional FMLs (carbon- and glass-based) with those made of core polyester foam. The amount of energy absorbed by the foam fibre metal laminates was greater than that of the conventional FMLs. Abdullah and Cantwell [21] investigated the impact resistance of hot-pressed polypropylene-based FMLs. The high strain to failure of the polypropylene fibres generates large values of absorbed energy during the failure process, therefore enhancing the perforation resistance of these layered structures. The highest specific perforation energy was provided by a simple sandwich construction with a thick composite core and thin outer aluminium plies. These findings also motivated the authors to investigate bio-based FMLs composed of simple sandwich configurations [11].

In previous work, Vieira et al. [11] investigated the mechanical properties of sisal fibrereinforced aluminium laminates (SiRAL) under static loads. The present work describes the dynamic response of SiRALs using drop tower impact testing and its effect on damage, propagation and fracture mode based on different composite core configurations. In addition, the influence of the surface treatment of aluminium skins is here considered. Analysis of variance (ANOVA) and design of experiment (DoE) are carried out to identify the effects of the fibre orientation (FO) and $\mathrm{Al}$ treatment (Al T) factors on the impact responses. Based on the authors' knowledge, the work presented in this paper represents the first attempt to study the behaviour of natural fibre-based metal laminates in low kinetic energy impacts using drop tower tests. 


\section{Materials and Methods}

\subsection{Materials}

The sisal fabric plain weave used in this work was $2 \mathrm{~mm}$ thick and supplied by APAEB Sisal (Brazil). The sisal fabric and the random short sisal fibre blanket had the same apparent density of $1300 \mathrm{~g} / \mathrm{m}^{2}$. A $0.40 \mathrm{~mm}$ thick $2024 \mathrm{~T} 3$ aluminium alloy was used as a facing material. The epoxy polymer (Type M) and the hardener (HY951) were supplied by Huntsman (Brazil).

\subsection{Preparation and Testing}

Sixty SiRALs were produced, considering three fibre orientations $\left(0^{\circ} / 90^{\circ},+45^{\circ} /-45^{\circ}\right.$ and random) and two aluminium skins (treated and untreated sheets). The aluminium sheets were sanded ( 80 grit) and then cleaned with a $10 \%$ wt $\mathrm{NaOH}$ solution. The aluminium skins were spray-coated with a commercial primer, Lazzuril Primer 045 (Sherwin Williams).

The laminates were manufactured by stacking two aluminium alloy sheets and the sisal fabric/matt epoxy core using a hand layup process, followed by uniaxial cold compaction at $1500 \mathrm{~Pa}$ (Figure 1a,b). The sisal matt is a cross-ply fabric supplied by Sisalsul (Brazil). The fabric was oriented within the mould at $0^{\circ} / 90^{\circ}$ and $+45^{\circ} /-45^{\circ}$ considering as reference the $0^{\circ}$ along the $x$-axis (Figure $1 \mathrm{a}$ ). After curing, individual SiRAL samples were obtained by cutting the sandwich panels with a precision saw. The matrix appeared homogeneously distributed without evidence of internal micro-voids (Figure 1c).

(a)

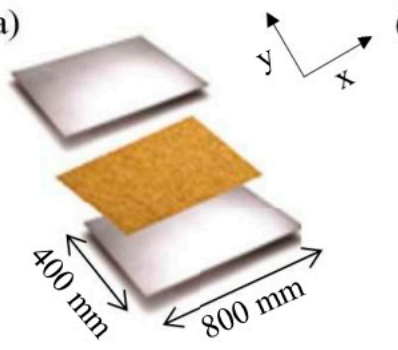

(b)

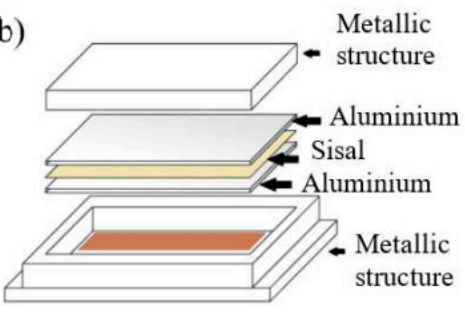

(c)

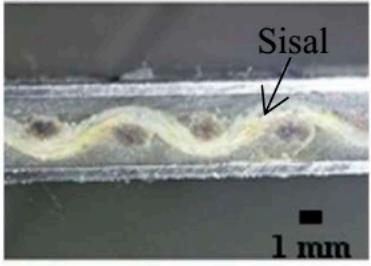

Figure 1. (a,b). Preparation scheme. (c) Cross-section of a SiRAL.

\subsubsection{Drop Tower Impact Tests}

The bending impact tests were performed using an Instron Dynatup 9250 HV impact tower testing machine (Figure 2c) with a $16 \mathrm{~mm}$ diameter hemispherical striker tip (Figure 2b). The tests were carried out at $3.35 \mathrm{~m} / \mathrm{s}$ and $1195 \mathrm{~mm}$ drop height (Figure 2a), corresponding to $40 \mathrm{~J}$ of energy. During the tests, the steel impactor always rebounded after the hit and was caught by the pneumatic brake to avoid undesirable extra strikes. The dimensions of the specimen $\left(150 \times 100 \times 4 \mathrm{~mm}^{3}\right)$ and the rectangular opening $\left(75 \times 125 \mathrm{~mm}^{2}\right)$ are based on the ASTM D7136 [22] standard. The $x$-axis sample orientation shown in Figure $1 \mathrm{a}$ corresponds to the direction of the larger opening side, i.e., $125 \mathrm{~mm}$. The SiRAL specimens were tested 3 months after being produced. Four clamps (Figure 2d) were used to restrain the specimen during the impact, where their location could influence the contact force's magnitude and the total duration of the impact [23]. Tape markers are used to ensure exact sample placement and indenter contact point. Fractured specimens were analysed using a low magnification optical microscope on the target's surfaces to understand the underpinning failure mechanisms. 

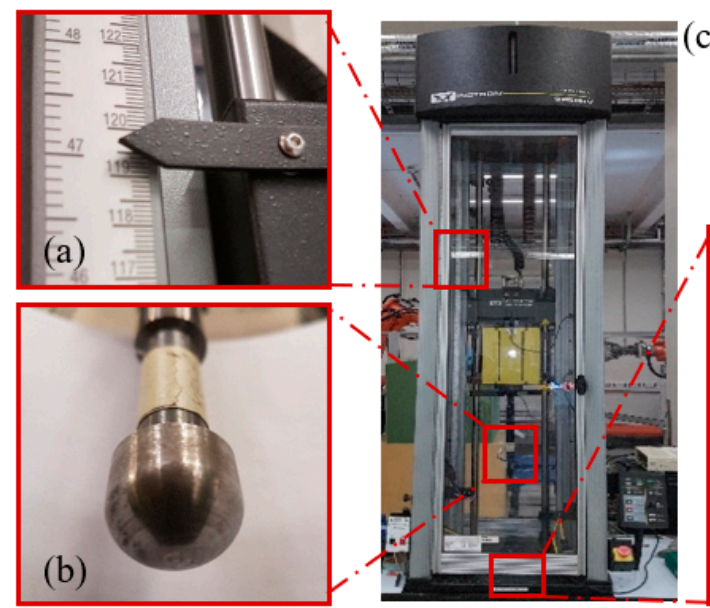

(c)

(b)
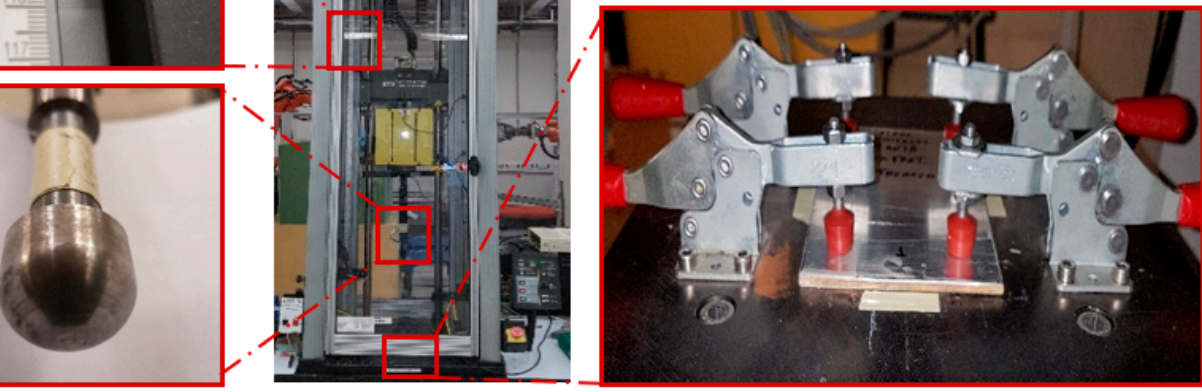

(d)

Figure 2. Impact test: (a) initial setup; (b) indentor; (c) overview of the drop tower machine; (d) fixtures for the samples.

\subsubsection{Apparent Density}

The apparent density of the SiRALs is calculated as the ratio between the mass of a given volume of the impermeable portion of the material and the mass of an equal volume of demineralised water at the same temperature (ASTM Standard D792) [24]. A desiccator and a vacuum pump (at approx. 1 bar) were used to saturate the material with water at $23 \pm 2{ }^{\circ} \mathrm{C}$ for $24 \mathrm{~h}$. Five samples for each condition were analysed.

\section{Results and Discussions}

\subsection{Impact Properties}

Table 1 shows the average and standard deviations of the impact responses. The data include two replicates with five samples each. The impact properties consist of total energy, maximum load, deflection and time to maximum load.

Table 1. Impact properties of the SIRAL specimens.

\begin{tabular}{ccccc}
\hline SiRAL Condition & $\begin{array}{c}\text { Total Energy } \\
{[\mathrm{J}]}\end{array}$ & $\begin{array}{c}\text { Max Load } \\
{[\mathrm{Kn}]}\end{array}$ & $\begin{array}{c}\text { Total Deflection } \\
{[\mathrm{mm}]}\end{array}$ & $\begin{array}{c}\text { Time to Max Load } \\
{[\mathrm{ms}]}\end{array}$ \\
\hline $0^{\circ} / 90^{\circ}$ & $31.77 \pm 0.72$ & $5.44 \pm 0.25$ & $9.16 \pm 1.21$ & $4.53 \pm 0.50$ \\
\hline $0^{\circ} / 90^{\circ}$ Al-Treated & $32.76 \pm 0.89$ & $4.13 \pm 0.33$ & $12.18 \pm 1.38$ & $6.36 \pm 0.48$ \\
\hline$+45^{\circ} /-45^{\circ}$ & $32.09 \pm 0.86$ & $5.99 \pm 0.46$ & $7.34 \pm 1.14$ & $3.65 \pm 0.67$ \\
\hline$+45^{\circ} /-45^{\circ}$ Al-Treated & $34.05 \pm 0.62$ & $3.81 \pm 0.20$ & $12.63 \pm 1.29$ & $4.47 \pm 1.52$ \\
\hline Random & $31.61 \pm 0.69$ & $6.33 \pm 0.27$ & $7.73 \pm 0.49$ & $3.98 \pm 0.46$ \\
\hline Random Al-Treated & $33.56 \pm 0.76$ & $4.17 \pm 0.22$ & $10.91 \pm 0.82$ & $5.67 \pm 0.61$ \\
\hline
\end{tabular}

Table 2 shows the analysis of variance (ANOVA) of the responses. $p$-values, less or equal to 0.05 , reveal significant factors or interactions that affect responses. The $p$-values in bold correspond to significant second-order effects, which will be evaluated via interaction plots. Higher $\mathrm{R}^{2}$ and Ryan-Joiner index values indicate that the models fit well with the data, validating the ANOVA. F-values can be used to compare the effects of each factor. Higher F-values indicate the factor that most contributes to the response variation. In this case, as shown in Table 2, aluminium treatment is the main factor affecting impact properties, especially the maximum impact load. 
Table 2. Analysis of variance (ANOVA).

\begin{tabular}{|c|c|c|c|c|c|c|}
\hline \multirow{2}{*}{ Experimental Factors } & \multicolumn{2}{|c|}{ Total Energy } & \multicolumn{2}{|c|}{ Total Deflection } & \multicolumn{2}{|c|}{ Max Load } \\
\hline & $p$-Values $(\leq 0.05)$ & F-Value & $p$-Values $(\leq 0.05)$ & F-Value & $p$-Values $(\leq 0.05)$ & F-Value \\
\hline Fibre orientation (FO) & 0.005 & 14.25 & 0.009 & 11.43 & 0.002 & 20.57 \\
\hline Al Treatment (Al T) & 0.000 & 174.46 & 0.000 & 276.29 & 0.000 & 940.27 \\
\hline $\mathrm{FO} \times \mathrm{Al} \mathrm{T}$ & 0.030 & 6.69 & 0.013 & 9.92 & 0.002 & 21.65 \\
\hline$R^{2}$ (adj) & $95.05 \%$ & & $96.62 \%$ & & $98.93 \%$ & \\
\hline Ryan-Joiner & 0.057 & & $>0.100$ & & $>0.100$ & \\
\hline
\end{tabular}

Figure 3 shows some typical load histories of the conditions tested. The treated $\mathrm{Al}$ panels reach the lowest maximum load and the highest absorbed total energy, deflection and time to maximum load (Table 1). In this sense, the treated aluminium skins provide a higher capacity for absorbing impact energy. This behaviour can be explained mainly by considering (i) the fragile interfacial bond between the skins and the core, and (ii) the high deflection of the core composite material. The impact load is first transferred to the skin material as normal stress, with subsequent shear deformations at the interface and core, similar to the bending behaviour. When a rigid and fragile bond at the interface is present, a sudden delamination occurs; thus, the core material is subjected to premature loading, causing it to deflect more than in the presence of a more ductile interface. The oscillation of the treated $\mathrm{Al}$ samples' reaction force indicates the fraying of the sisal fibres, which is commonly observed in natural reinforcements under normal stress [8,25]. Additionally, especially for the case of the treated $\mathrm{Al}$ samples, the crack propagating along the interface consumes more energy at the beginning of the test, with a subsequent drop after delamination. This behaviour can be ascertained by observing the peak load (P1), with a more extended signal period typically associated with delaminated specimens [23]. In contrast, the untreated Al skin samples show a less rigid interfacial bonding with higher impact loads and lower energy absorption. The impact behaviour of the sandwich panels is generally opposite to the one observed during the static bending tests. Skin-core delamination $[26,27]$ and/or fibre pull-out [28] are considered to be between the main energy absorption mechanisms acting under dynamic loads. The treated SiRALs provide not only a premature delamination, but also larger deflections, including in the composite core. Premature delamination and deflections contribute to absorbing more impact energy. In contrast, the untreated skins withstand larger impact loads because of the less premature delamination occurring in those samples, with a consequent reduction in bending deflection.

Figure 4 shows examples of delaminated samples made with treated $(\mathrm{a}-\mathrm{c})$ and untreated $(\mathrm{d}-\mathrm{f})$ aluminium skins after impact. There is no evidence of perforation of the bottom skins; however, macro-cracks are present in the samples with untreated Al skins.

The damage induced by the impact on the SiRALs can be divided into two categories: (i) visible damage in the form of local plastic indentation and (ii) internal damage represented by fibre failure, matrix cracking and delamination. SiRALs exhibit the distinctive characteristics of impact deformation and cracking (see Table 3). Treated Al sheets provide larger deflections, including wrinkling of the upper skin metal sheet; the latter deformation mechanism is mainly attributed to premature delamination.

The area marked in black in Figure 5 highlights the cracks for each core material reinforced with fibres oriented at $0^{\circ} / 90^{\circ}$ (Figure 5a), $\pm 45^{\circ}$ (Figure 5b) and randomly (Figure $5 \mathrm{c}$ ). Sisal fibre composites oriented at $0^{\circ} / 90^{\circ}$ show a crack propagation along the longitudinal direction of the sample (Figure 5a). Cores made with $\pm 45^{\circ}$ fibre orientation show a diagonal crack following the $45^{\circ}$ fabric orientation (Figure $5 b$ ). X-shaped cracks are evident in those cores reinforced with random fibres (Figure $5 \mathrm{c}$ ). Therefore, random sisal fibres appear to dissipate the impact energy over a larger area in different directions and sustain the highest impact load (Table 1). 

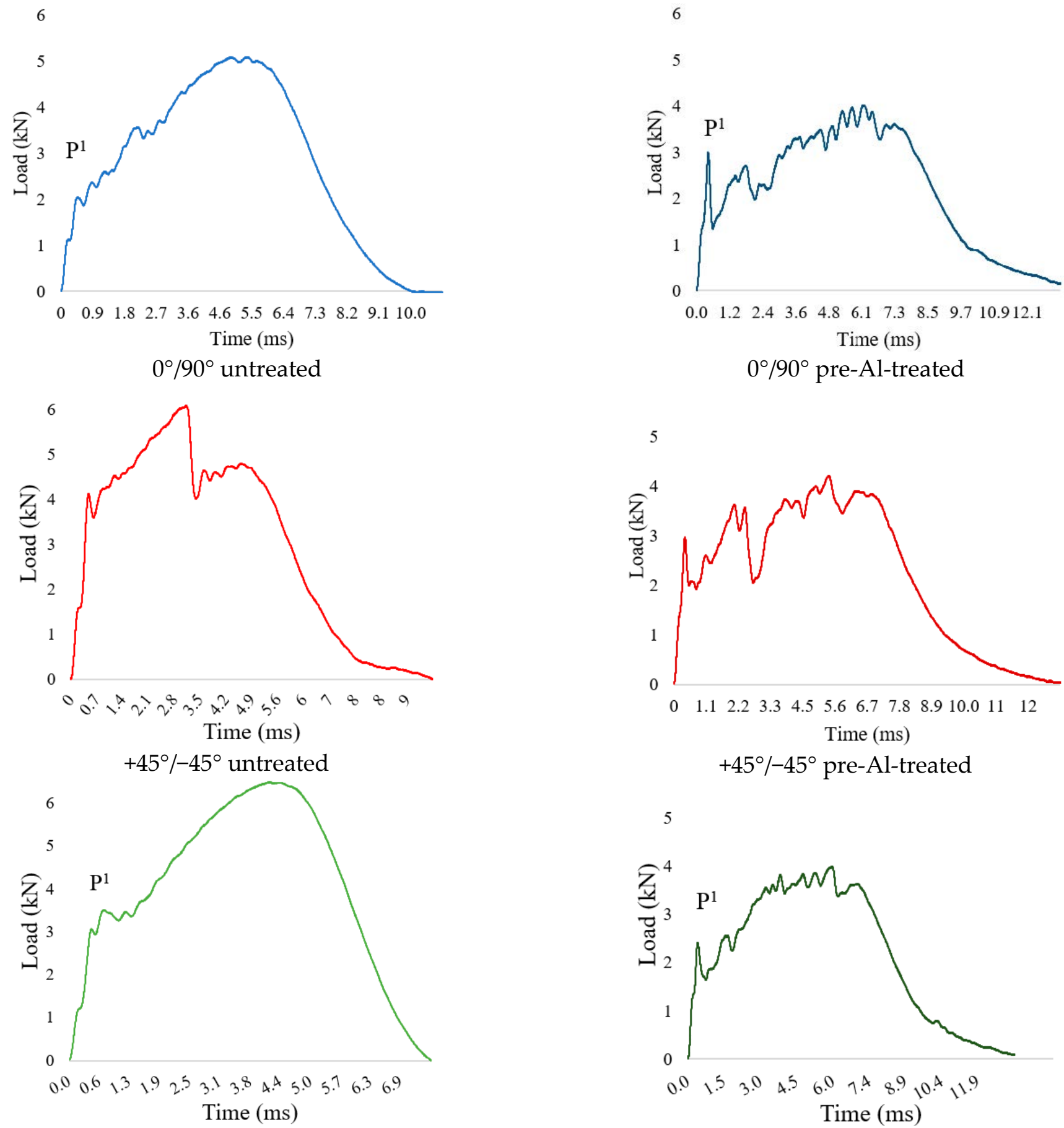

Random untreated

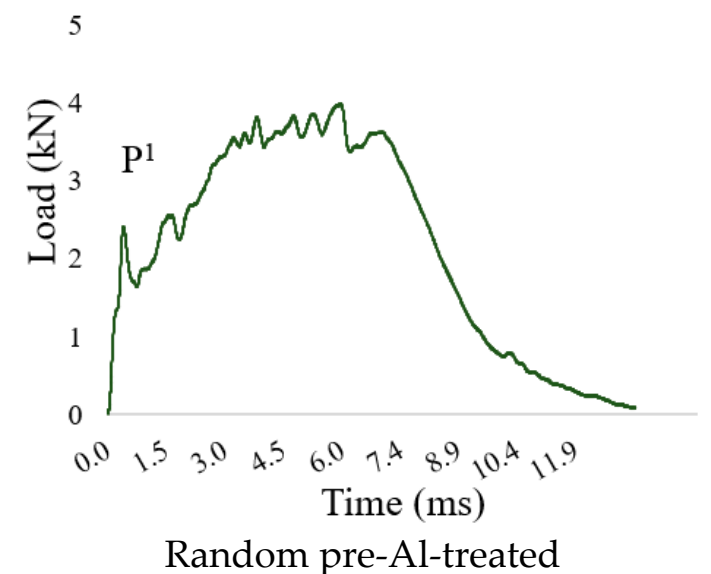

Figure 3. Typical impact curves for SiRALs. 

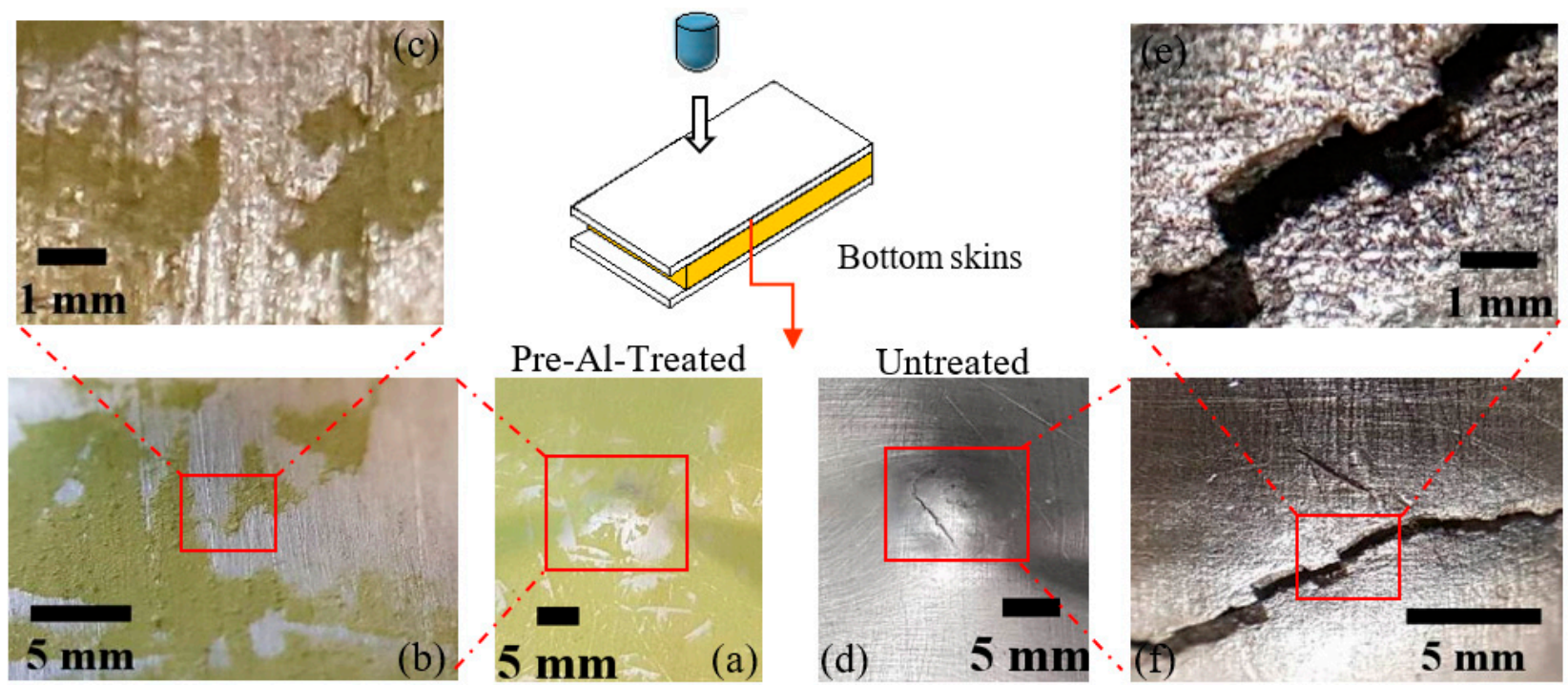

Figure 4. Bottom skins after test: $(\mathbf{a}-\mathbf{c})$ treated $\mathrm{Al}$ and $(\mathbf{d}-\mathbf{f})$ untreated $\mathrm{Al}$.
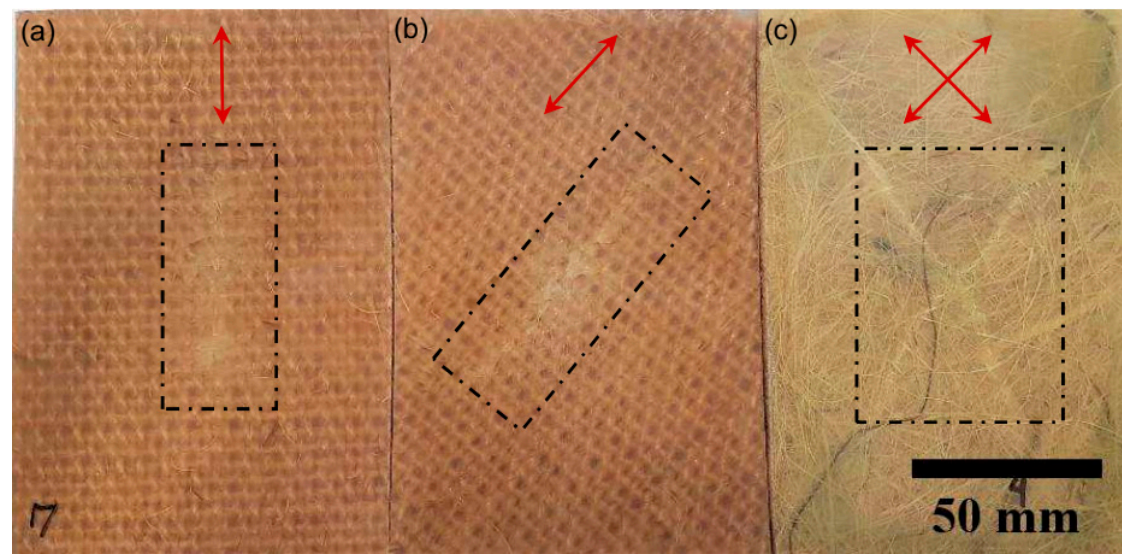

Figure 5. Typical cracks for (a) $0^{\circ} / 90^{\circ}$, (b) $\pm 45^{\circ}$ and (c) randomly oriented fibre cores.

Table 3. Impact damage of SIRALs.

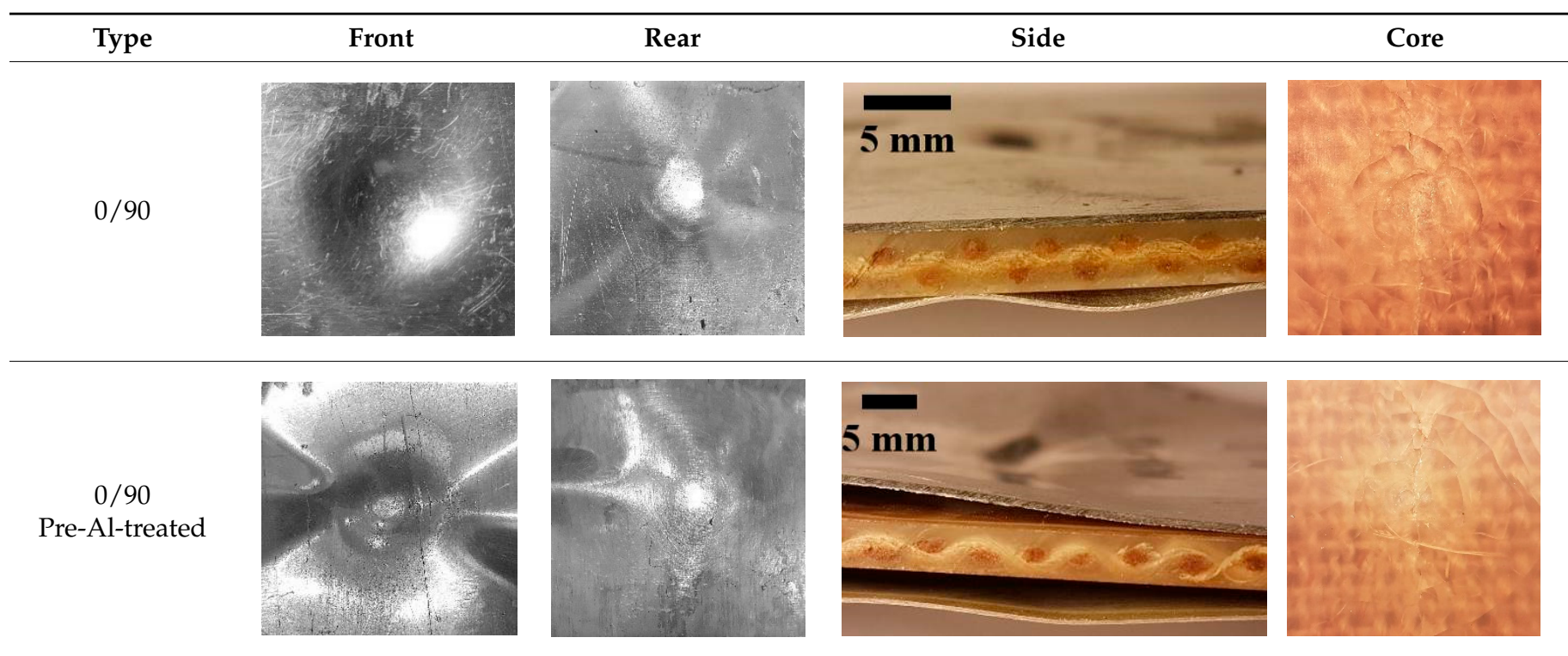


Table 3. Cont.

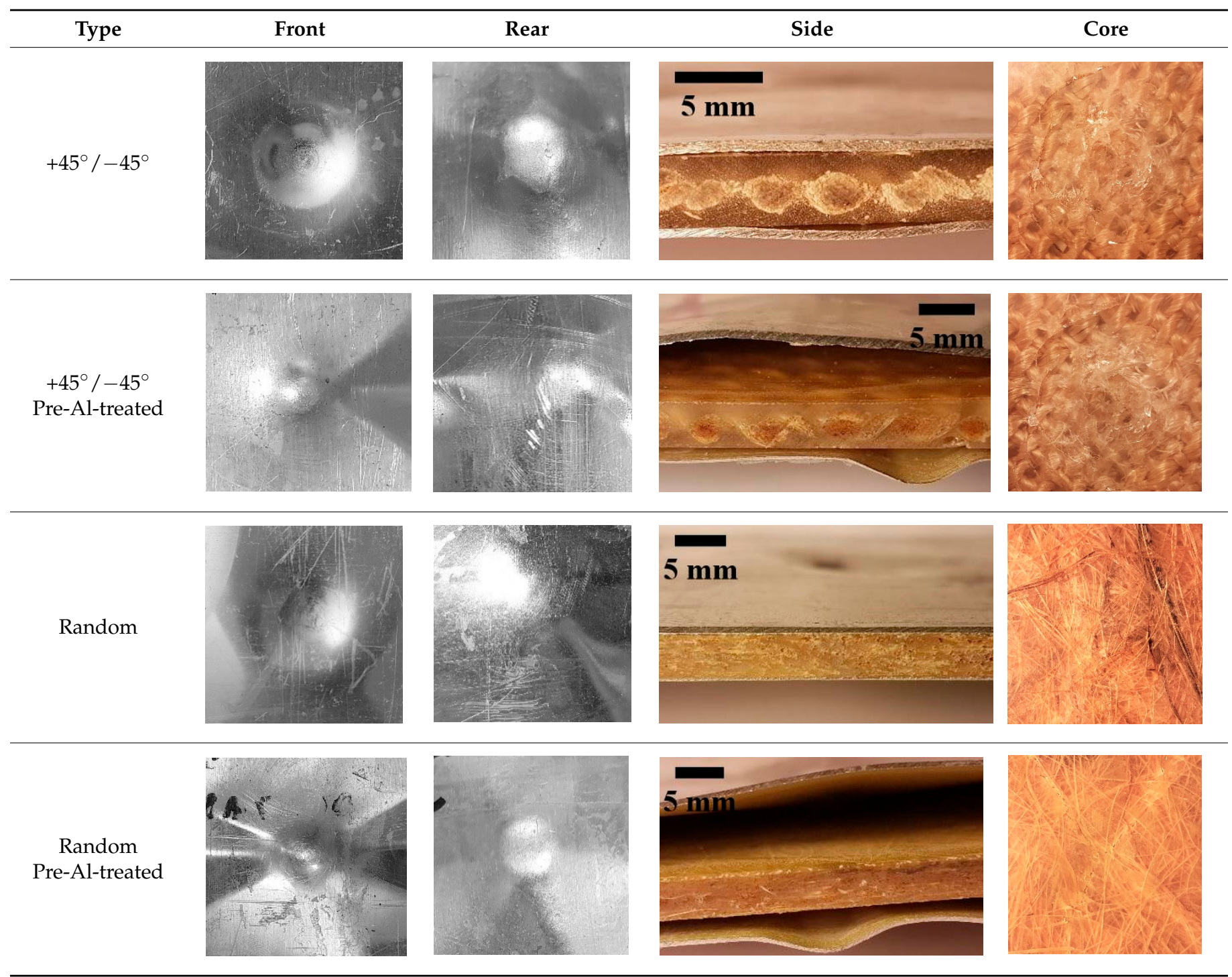

\subsubsection{Maximum Load}

Figure 6a shows the interaction plot associated with the mean (average) maximum load response. Al-treated FMLs show a $\sim 36 \%$ reduction in peak load, which is attributed to the premature delamination between the aluminium sheets and the core. Although the bond between aluminium and epoxy polymers can be significantly enhanced using treatments on the metal surface [29], the primer used in this work was not adequate to delay the delamination process.

Randomly oriented fibre cores lead to increased impact loads $(6.3 \pm 0.27 \mathrm{kN})$, which are $\sim 16 \%$ and $10 \%$ higher than those associated with fibres oriented at $\pm 45^{\circ}$ and $0^{\circ} / 90^{\circ}$, respectively (Figure 6a). It is worth noting that the fibre volume fraction of random fibre cores is greater than that of woven cores. The latter also appear to be inhomogeneous and feature empty spaces (voids) (see Table 3), reducing the fibres to effectively transfer the applied loads. 


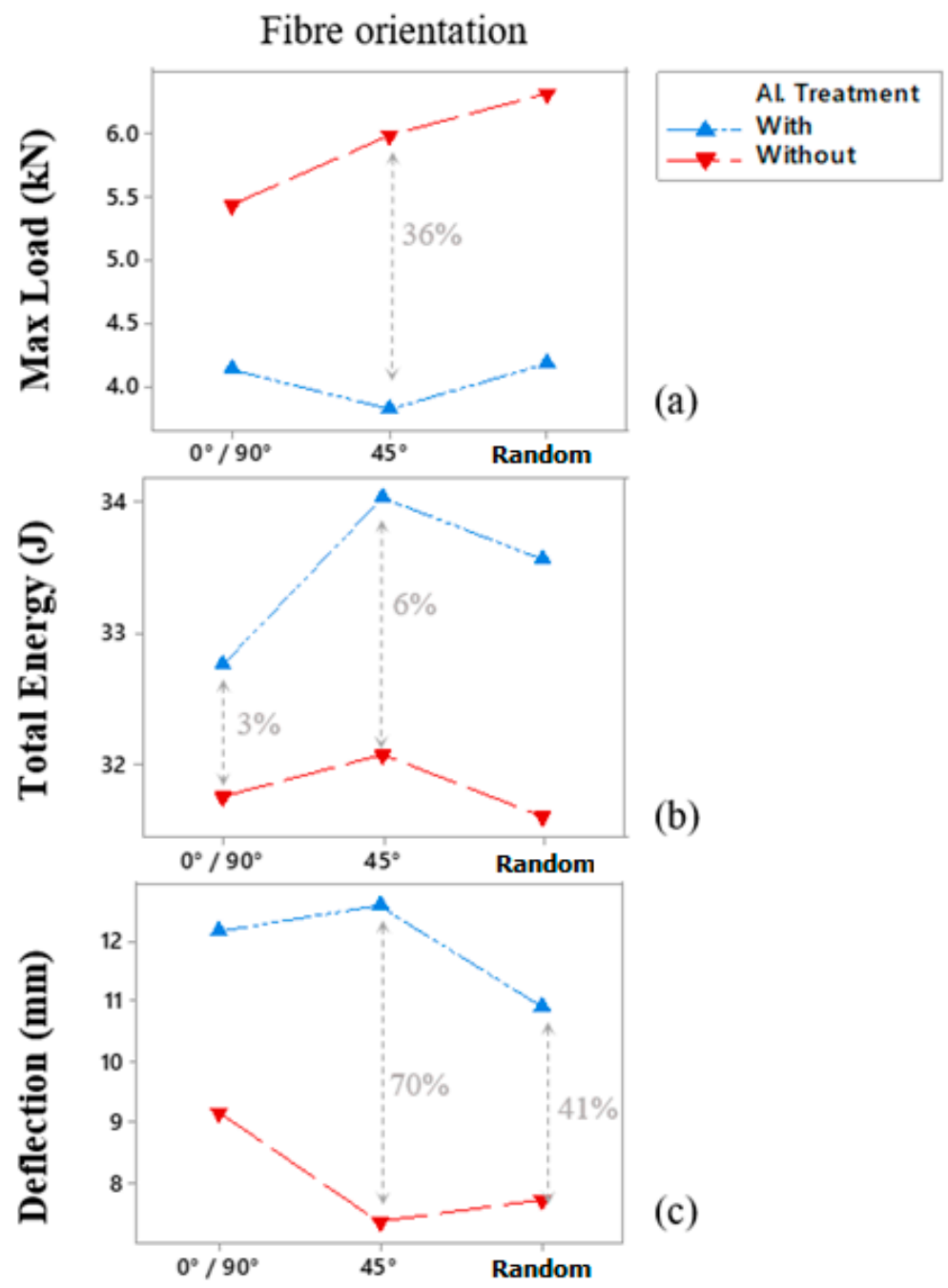

Figure 6. Interaction plot representing the maximum load (a), the total energy (b) and maximum deflection (c).

\subsubsection{Total Energy}

Figure $6 \mathrm{~b}$ shows the second-order interaction effect plot associated with the mean (average) impact total energy. Treated aluminium panels feature the highest total energy values, especially when the $\pm 45^{\circ}$ oriented fibre core is used. The impact energy is directly related to the material deformation $[17,30]$. As discussed previously, the treated $\mathrm{Al}$ sheets exhibit a global delamination behaviour that contributes to a greater core deflection and a consequent increase in energy.

\subsubsection{Maximum Deflection}

The interaction effect plot related to the mean (average) impact deflection is presented in Figure $6 \mathrm{c}$. SiRALs made with a $\pm 45^{\circ}$ fibre orientation core achieve the highest and the lowest deflections for the treated and untreated Al sheets cases, respectively. The larger delamination in treated $\mathrm{Al}$ skin samples is also responsible for a substantial deflection in all fibre orientations.

\section{Conclusions}

This work described the drop-weight impact properties of sisal fibre-reinforced aluminium laminates (SiRALs), and the main conclusions are:

i. The ANOVA revealed that all individual factors and their interactions affect impact properties; however, aluminium treatment is the most contributing factor. 
ii. Sisal fibre orientation affects the fracture behaviour of the panels. Cores made with $0^{\circ} / 90^{\circ}$ fibres lead to longitudinal fractures $\left(90^{\circ}\right)$. Randomly oriented fibre cores show an X-shaped fracture that extends to the end of the sample. Cores made of fibres oriented at $\pm 45^{\circ}$ exhibit crack propagation along the diagonal direction of the laminate, with significant impact energy dissipation.

iii. Treated aluminium panels sustain the lowest values of maximum loads, with higher levels of total energy, deflection and time to maximum load. This effect is mainly attributed to premature delamination between the core and the skins, including the wrinkling effect of the upper skin metal sheet.

iv. In contrast, FMLs with untreated aluminium sheets provide the highest maximum impact loads with a less rigid surface bonding and reduced delamination effect.

v. Skin-core delamination and/or fibre pull-out are considered to be energy absorption mechanisms acting under dynamic loads.

vi. There is no perforation of the bottom skins; however, macro-cracks are commonly present in the untreated aluminium samples.

vii. Panels composed of cores made from random fibres or $\pm 45^{\circ}$ sisal fabric along the untreated aluminium skins provide the lowest deflections.

viii. Random sisal fibres induce the dissipation of impact energy over a larger area in different directions, leading to greater impact load.

ix. SiRALs made with a random fibre core and untreated aluminium sheets give the highest maximum impact load $(6.3 \mathrm{kN})$. However, FMLs with $\pm 45^{\circ}$ fibre-oriented cores with treated $\mathrm{Al}$ skins provide the highest deflection $(12 \mathrm{~mm})$ and total impact energy $(34 \mathrm{~J})$.

x. Sisal fibre-reinforced aluminium laminates (SiRALs) are very promising in several areas of engineering. They could be used, for example, in civil construction sectors such as room partitions, signage and wall coverings. SiRALs combine sustainability, low cost and structural performance.

Author Contributions: Conceptualization, T.H.P. and J.C.C.R.; methodology, T.H.P.; formal analysis, L.M.G.V.; investigation, L.M.G.V., J.C.d.S. and Y.D.; resources, T.H.P., J.C.C.R. and F.S.; data curation, L.M.G.V.; writing—original draft preparation, L.M.G.V. and J.C.d.S.; writing-review and editing, T.H.P. and F.S.; supervision, T.H.P., J.C.C.R. and F.S.; project administration, T.H.P. and J.C.C.R.; funding acquisition, J.C.C.R. and T.H.P. All authors have read and agreed to the published version of the manuscript.

Funding: This research was funded by the Brazilian Research Agencies, FAPEMIG (PPM), CAPES (PhD scholarship) and CNPq (PQ 309885/2019-1 and 394208/2019-1).

Data Availability Statement: No new data were created or analyzed in this study. Data sharing is not applicable to this article.

Acknowledgments: The authors would like to thank the Brazilian Research Agencies, CNPq, FAPEMIG and CAPES, for the financial support granted, the University of Bristol and the Bristol Composites Institute for the support provided.

Conflicts of Interest: The authors declare no conflict of interest.

\section{References}

1. Cortés, P.; Cantwell, W.J. The Impact Properties of High-temperature Fiber-Metal Laminates. J. Compos. Mater. 2006, 41, 613-632. [CrossRef]

2. Vogelesang, L.; Vlot, A. Development of fibre metal laminates for advanced aerospace structures. J. Mater. Process. Technol. 2000, 103, 1-5. [CrossRef]

3. Sinmazçelik, T.; Avcu, E.; Bora, M.Ö.; Çoban, O. A review: Fibre metal laminates, background, bonding types and applied test methods. Mater. Des. 2011, 32, 3671-3685. [CrossRef]

4. McCombe, G.; Etches, J.; Mellor, P.; Bond, I. Development of a ferromagnetic fibre metal laminate. Compos. Part A Appl. Sci. Manuf. 2011, 42, 1380-1389. [CrossRef]

5. Carrillo, J.; Cantwell, W. Mechanical properties of a novel fiber-metal laminate based on a polypropylene composite. Mech. Mater. 2009, 41, 828-838. [CrossRef] 
6. Rao, K.M.M.; Prasad, A.R. Fabrication and testing of natural fibre composites: Vakka, sisal, bamboo and banana. Mater. Des. 2010, 31, 508-513. [CrossRef]

7. Yusoff, R.B.; Takagi, H.; Nakagaito, A.N. Tensile and flexural properties of polylactic acid-based hybrid green composites reinforced by kenaf, bamboo and coir fibers. Ind. Crop. Prod. 2016, 94, 562-573. [CrossRef]

8. Vieira, L.M.G.; dos Santos, J.C.; Panzera, T.H.; Christoforo, A.L.; Mano, V.; Rubio, J.C.C.; Scarpa, F. Hybrid composites based on sisal fibers and silica nanoparticles. Polym. Compos. 2018, 39, 146-156. [CrossRef]

9. Vasumathi, M.; Murali, V. Effect of Alternate Metals for use in Natural Fibre Reinforced Fibre Metal Laminates under Bending, Impact and Axial Loadings. Procedia Eng. 2013, 64, 562-570. [CrossRef]

10. Zhang, J. Static indentation and impact behaviour of reformed bamboo/aluminium laminated composites. Compos. Struct. 2000, 50, 207-216. [CrossRef]

11. Vieira, L.M.G.; dos Santos, J.C.; Panzera, T.H.; Rubio, J.C.C.; Scarpa, F. Novel fibre metal laminate sandwich composite structure with sisal woven core. Ind. Crop. Prod. 2017, 99, 189-195. [CrossRef]

12. Malingam, S.D.; Feng, N.L.; Khoon, L.C.; Fadzullah, S.S.M.; Mustafa, Z.; Subramonian, S. The Influences of Fibre Parameters on the Tensile and Flexural Response of Lightweight Thermoplastic Kenaf Fibre Reinforced Metal Composites. J. Nat. Fibers 2018, 17, 966-978. [CrossRef]

13. Hussain, M.; Imad, A.; Saouab, A.; Kanit, T.; Nawab, Y.; Herbelot, C.; Kashif, M. Properties and characterization of novel 3D jute reinforced natural fibre aluminium laminates. J. Compos. Mater. 2021, 55, 1879-1891. [CrossRef]

14. Sevkat, E.; Liaw, B.; Delale, F. Drop-weight impact response of hybrid composites impacted by impactor of various geometries. Mater. Des. 2013, 52, 67-77. [CrossRef]

15. Deng, Y.; Zhang, W.; Cao, Z. Experimental investigation on the ballistic resistance of monolithic and multi-layered plates against hemispherical-nosed projectiles impact. Mater. Des. 2012, 41, 266-281. [CrossRef]

16. Laliberté, J.; Poon, C.; Straznicky, P.; Fahr, A. Post-impact fatigue damage growth in fiber-metal laminates. Int. J. Fatigue 2002, 24, 249-256. [CrossRef]

17. Li, X.; Yahya, M.Y.; Nia, A.B.; Wang, Z.; Lu, G. Dynamic failure of fibre-metal laminates under impact loading-Experimental observations. J. Reinf. Plast. Compos. 2016, 35, 305-319. [CrossRef]

18. Lee, D.-W.; Park, B.-J.; Park, S.-Y.; Choi, C.-H.; Song, J.-I. Fabrication of high-stiffness fiber-metal laminates and study of their behavior under low-velocity impact loadings. Compos. Struct. 2018, 189, 61-69. [CrossRef]

19. Dhaliwal, G.S.; Newaz, G.M. Effect of Layer Structure on Dynamic Response and Failure Characteristics of Carbon Fiber Reinforced Aluminum Laminates (CARALL). J. Dyn. Behav. Mater. 2016, 2, 399-409. [CrossRef]

20. Saniei, S.M.; Mashroteh, H.; Hadizadeh, M. An investigation into low-velocity impact resistance and tensile strength of aluminiumglass fabric hybrid composite. IOP Conf. Ser. Mater. Sci. Eng. 2017, 254, 42026. [CrossRef]

21. Abdullah, M.; Cantwell, W. The impact resistance of polypropylene-based fibre-metal laminates. Compos. Sci. Technol. 2006, 66, 1682-1693. [CrossRef]

22. ASTM Standard D7136/D7136M-15; Standard Test Method for Measuring the Damage Resistance of a Fi-ber-Reinforced Polymer Matrix Composite to a Drop-Weight Impact Event. ASTM International: West Conshohocken, PA, USA, 2015.

23. Feraboli, P. Some Recommendations for Characterisation of Composite Panels by Means of Drop Tower Impact Testing. J. Aircr 2006, 43, 1710-1718. [CrossRef]

24. ASTM Standard D792/D792; Standard Test Methods for Density and Specific Gravity (Relative Density) of Plastics by Displacement. ASTM International: West Conshohocken, PA, USA, 2013.

25. da Silva, L.J.; Panzera, T.H.; Velloso, V.R.; Christoforo, A.L.; Scarpa, F. Hybrid polymeric composites reinforced with sisal fibres and silica microparticles. Compos. Part B Eng. 2012, 43, 3436-3444. [CrossRef]

26. de Oliveira, L.Á.; Tonatto, M.L.P.; Coura, G.L.C.; Freire, R.T.S.; Panzera, T.H.; Scarpa, F. Experimental and numerical assessment of sustainable bamboo core sandwich panels under low-velocity impact. Constr. Build. Mater. 2021, 292, 123437. [CrossRef]

27. Oliveira, P.; Kilchert, S.; May, M.; Panzera, T.; Scarpa, F.; Hiermaier, S. Numerical and experimental investigations on sandwich panels made with eco-friendly components under low-velocity impact. J. Sandw. Struct. Mater. 2021, 24, 419-447. [CrossRef]

28. Filho, S.L.M.R.; Oliveira, P.R.; Panzera, T.H.; Scarpa, F. Impact of hybrid composites based on rubber tyres particles and sugarcane bagasse fibres. Compos. Part B Eng. 2019, 159, 157-164. [CrossRef]

29. Xu, Y.; Li, H.; Shen, Y.; Liu, S.; Wang, W.; Tao, J. Improvement of adhesion performance between aluminum alloy sheet and epoxy based on anodizing technique. Int. J. Adhes. Adhes. 2016, 70, 74-80. [CrossRef]

30. Feraboli, P.; Kedward, K.T. Enhanced Evaluation of the Low-Velocity Impact Response of Composite Plates. AIAA J. 2004, 42, 2143-2152. [CrossRef] 